\title{
STATISTICAL ANALYSIS OF THE EFFECTS OF DISRUPTIVE FACTORS OF DRIVING IN SIMULATED ENVIRONMENT
}

\author{
Gábor PAUER, Tibor SIPOS, Árpád TÖRÖK* \\ Dept of Transport Technology and Economics, Faculty of Transportation Engineering and Vehicle Engineering, \\ Budapest University of Technology and Economics, Hungary
}

Received 17 October 2017; revised 27 November 2017; accepted 25 April 2018

\begin{abstract}
Distracting activities (such as using mobile phones, writing text messages) become increasingly common with the widespread use of telecommunication devices, becoming an increasing problem of road safety. Our research aimed to show the effects of these disruptive factors on driving. To quantify the effects, simulator tests have been performed. To analyse the significance of the changes caused by the disruptive factors, mathematical-statistical methods have been applied and conclusions for all drivers have been drawn. The effects of the disruptive factors have been quantified. On the one hand, the cognitive distraction and the hindrance of movements affects negatively the road safety, and on the other hand results in negative environmental and economic effects. Based on the numerical results of the research, hitting speeds caused by the disruptive factors have been determined as an example. The results of the research can be used as input data for the quantification of economic and environmental effects of road safety caused by disruptive factors and for the establishment of the background of legislation related to the prohibition of these factors.
\end{abstract}

Keywords: disruptive factors, distraction, simulated environment, statistical analysis, road safety.

\section{Introduction}

The participants of the High Level Group (HLG) on road safety declared that the attention distracting activities, devices and effects while driving are a growing issue from a road safety point of view and requiring immediate actions (Török 2017). Due to the severity of the problem, the HLG indicated to the Commission, that an analysing-evaluating assessment of each Member State is needed to develop the possible packages of measures. In accordance with that, the aim of our research was to quantify the effects of the disruptive factors.

There are several sources of the inattention of drivers (factors inside or outside the vehicle, thoughts, etc.). The 4 major types of disturbance are:

- visual (e.g. text messaging);

- cognitive (e.g. focus on phone conversation);

- physical (e.g. holding a bottle in one hand);

- auditive (e.g. phone ringing) (Regan et al. 2008).

In the case of distraction the driver's recognition of the information needed for safe driving is slower, thus the risk of accidents increases (Treat 1980; Bartl, Hager 2006). The main factor of the increasing accident risk is the diversion of the driver's attention (Beanland et al. 2013). Based on the results of an American research, in nearly $80 \%$ of the accidents, the driver was not paying attention to the road (Neale et al. 2005), so one of the inattention (distraction) types before the accident was observed, while an Austrian research showed that all of the cases examined from 474 accidents were caused by the diversion of the attention (Staubach 2009).

Researchers showed, that using the mobile phones and conversations with passengers entails 4 times higher risk of accidents (probably caused by the increased task load and increased response time) (Caird et al. 2008, 2014; Amado, Ulupınar 2005). Furthermore, text messaging is a more significant distraction (Hosking et al. 2009) causing increased lateral distance and following distance variability, and increased crash frequency (Drews et al. 2009). This phenomenon is a growing problem among young people, since they are more prone to use such devices (Prat et al. 2015; Russo et al. 2014).

Older people are less able to split their attention between two tasks, while disruptive effects reduce more the

${ }^{*}$ Corresponding author. E-mail: torok.arpad@mail.bme.hu 
novice drivers' performance (Young, Regan 2007). The more complex traffic environment, the bad weather conditions enhance the risk-increasing effect (McKnight, A. J., McKnight, A. S. 1993; Cooper, Zheng 2002; Strayer et al. 2003).

During our research, disruptive effects have been examined both in real driving environment and in the framework of simulator-based examinations. The aim of this study is to analyse the results of our simulator-based examinations.

Simulator based studies have revealed, that text messaging results more lane deviations and crashes, and has a significantly negative impact on traffic flow (Zefreh et al. 2017) among young drivers (Stavrinos et al. 2013). Combined with effects of alcohol intoxication, the risks were even higher when examining the position of the car and eye glances (Palumbo et al. 2015). Young adults have spent $400 \%$ more of the simulator time with their eyes-off of the road while texting than when undistracted (Hosking et al. 2009; Caird et al. 2014). Rumschlag et al. (2015) showed, that texting during simulated driving increased the frequency and severity of lane excursions, which were only correlated with the driver age at the group of skilled texters.

When conversing on a cell phone, the braking reactions of participants (ranged in age 22...34) were delayed and they were involved in more traffic accidents (reaction time increased by $9.3 \%$, more than in case of drinking alcohol) - Strayer et al. (2006). Traffic violations, attention lapses, and response time was significantly impacted even when young drivers were talking on a hand-free phone (Beede, Kass 2006). A simulator based study considering all age groups examined only the effects of wireless telephone use, and found that it increases the risk of collisions at crossings with traffic lights (Moreno, Romana 2015).

These studies aimed to show negative effects of distraction on traffic safety but did not examine all driver groups and various vehicle dynamics parameters to show environmental and economical effects. The main contribution of our study is that it is considering:

- all age groups;

- several different disrupting factors both on cognitive, physical and visual levels;

- complex vehicle dynamics parameters and driving characteristics beside traffic violations and mistakes.

It is important to emphasize the need of actual studies and numerical results. Although, many previous international researches have examined the effects of disruptive factors, these studies show a wide dispersion according to their results, methodology and factors considered, and a reasonable part of the literature identifies insignificant effect on crash modification factor (Fitch et al. 2013), which makes further investigations be necessary. This conclusion is also supported by the fact that though mobile phones while driving is prohibited in most of the countries - the acceptance of their usage is still very significant, for instance researches focusing on young drivers, measure the level of hand held mobile phone usage while driving still over 15\% (Szántó, Kibédi-Varga 2017). The use of mobile phones and texting are prohibited in many European countries, however road safety risks related to these devices are still unknown for many road users (Hermitte et al. 2016). Besides that, there are several new distributing factors (hands free phone equipment, touch screen phones, onboard navigation systems etc.) that have a negative impact on road safety. Education and raising-awareness are effective solutions of decreasing the problem related to these factors, for which it is strongly recommended to quantify the effects of distracting factors, as introduced in this research, as the effectiveness of these interventions relies on the assumption that people will opt for safe behaviour if they are provided with relevant, actual and concrete information, which attain awareness and insight (Šucha 2017).

\section{Methodology}

\subsection{The measurement process and parameters}

The measurements were carried out at a realistic car simulator. A total of 90 people participated in the measurement - 73 men and 17 women. The distribution of participants by age can be considered as representative. The following 2 different task types had to be fulfilled during the measurement, both with and without the effects of disruptive factors:

- Emergency management task. The drivers had to drive along a $3.6 \mathrm{~km}$ long highway section and stay on track in sunny, dry weather conditions. They had to pay special attention to comply on the Highway Code rules in force. Meanwhile they had to solve emergencies occurring in each round (such as deer, suddenly running across the road, etc.), to avoid potential accidents.

- Emergency braking task. The drivers had to speed up from a standstill to $100 \mathrm{~km} / \mathrm{h}$ speed on a highway's traffic-free section. Keeping this speed and recognizing a suddenly appearing STOP sign at a random part of the central monitor (windshield or the centre rear-view mirror) they had to stop immediately applying emergency braking. The STOP sign appeared at the monitor at a random place and at a random time.

The applied disruptive factors during the simulated analysis were the most common distracting activities in reality: using the mobile phone, drinking and text messaging. The disruptive factors distract the driver in visual terms, with the hindrance of movements, and by distracting attention, at a cognitive level. While text messaging, only the shorter emergency braking task had to be completed to avoid sickness of the drivers, which can distort the measurement results (Helland et al. 2016).

All the participants completed two rounds without disruptive factors and two rounds with each disruptive factor. The tasks and the factors followed each other alternately (e.g. the first round of reference emergency braking, 
without disruptive factors was held at the beginning of the measurement, while the other was at the end of the measurements). Table 1 summarizes the parameters recorded during the measurements.

\subsection{The methods of the evaluation of the results}

Mathematical-statistical methods have been applied during the evaluation. The aim of the analysis was to determine, whether the disruptive factors resulted in significant differences of the driving characteristics or not. The statistical methods applied by the evaluation provide an opportunity to view the results of the test sample as overall results of all drivers (at a specified confidence level).

The disruptive factors have been evaluated based on the average of the result of the two measurements round with the selected factor. Both the alternation of the tasks and the averaging of the measured results helped to eliminate the effect of the drivers learning the tracks and the obstacles. Averaging also "reduces" the standard deviation between the measurements. As an example, the calculation describing the average value of "number of insufficient distance between vehicles" factor is shown in Equation (1):

$$
\begin{aligned}
& A_{z}=\frac{A_{z}^{1}+A_{z}^{2}}{2} ; \\
& z=\{r ; t ; i\},
\end{aligned}
$$

where: $A_{z}$ is the average value of "number of insufficient distance between vehicles" factor in case of disruptive factor $z ; A_{z}^{1}$ and $A_{z}^{2}$ are the "number of insufficient distance between vehicles" respectively in the 1-st and 2-nd measured rounds in case of disruptive factor $z$.

The evaluation process of the significance of the differences of the driving parameters with and without disruptive factors has been summarized at Figure 1.

During the evaluations, it has been found, that the smaller driving mistakes of the emergency management task (insufficient distance between vehicles, misuse of direction indicator, lane positioning error) are more common than the severe mistakes causing more dangerous

\begin{tabular}{|c|c|c|c|}
\hline Task & Measured parameter & Unit & Notation \\
\hline \multirow{9}{*}{ 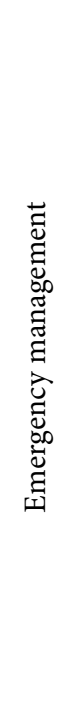 } & $\begin{array}{l}\text { number of insufficient } \\
\text { distance between } \\
\text { vehicles }\end{array}$ & number/person & $A_{z}^{n}$ \\
\hline & $\begin{array}{l}\text { number of misuse } \\
\text { of direction indicator }\end{array}$ & number/person & $B_{z}^{n}$ \\
\hline & $\begin{array}{l}\text { number of road sign } \\
\text { or barrage line faults }\end{array}$ & number/person & $C_{z}^{n}$ \\
\hline & $\begin{array}{l}\text { number of exceeding } \\
\text { maximum speed }\end{array}$ & number/person & $D_{z}^{n}$ \\
\hline & $\begin{array}{l}\text { number of lane } \\
\text { positioning error }\end{array}$ & number/person & $E_{z}^{n}$ \\
\hline & number of collisions & number/person & $F_{z}^{n}$ \\
\hline & average engine speed & $1 / \mathrm{min}$ & $G_{z}^{n}$ \\
\hline & average speed & $\mathrm{km} / \mathrm{h}$ & $H_{z}^{n}$ \\
\hline & $\begin{array}{l}\text { average fuel } \\
\text { consumption }\end{array}$ & $1 / 100 \mathrm{~km}$ & $I_{z}^{n}$ \\
\hline \multirow{3}{*}{ 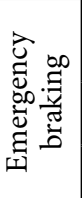 } & $\begin{array}{l}\text { braking initial speed } \\
(\text { allotted }=100 \mathrm{~km} / \mathrm{h})\end{array}$ & $\mathrm{km} / \mathrm{h}$ & $J_{z}^{n}$ \\
\hline & response time & s & $K_{z}^{n}$ \\
\hline & deceleration & $\mathrm{m} / \mathrm{s}^{2}$ & $L_{z}^{n}$ \\
\hline
\end{tabular}

Table 1. Measured factors

Notes: the possible values of index $n$ were 1 (at the 1 -st round with the selected disruptive factor); and 2 (at the 2-nd round); the possible values of index $z$ representing the disruptive factor were $r$ - reference measurement without disruptive factors; $t$ - phone usage); $i$ - drinking); $s$ - text messaging).

situations in road traffic (such as exceeding maximum speed, barrage line faults, collisions). The lower frequency of these severe cases distorts the evaluation, thus we introduced a new "indicator of mistakes" to evaluate them (notation - " $M$ "). Calculating this indicator, the averaged values of the 6 types of mistakes above were scaled between the values of $1 \ldots .5$ for every measurement specimen. The calculation is shown in Equation (2), describing the calculation of the scaled value of the number of "insufficient distance between vehicles" factor as an example.

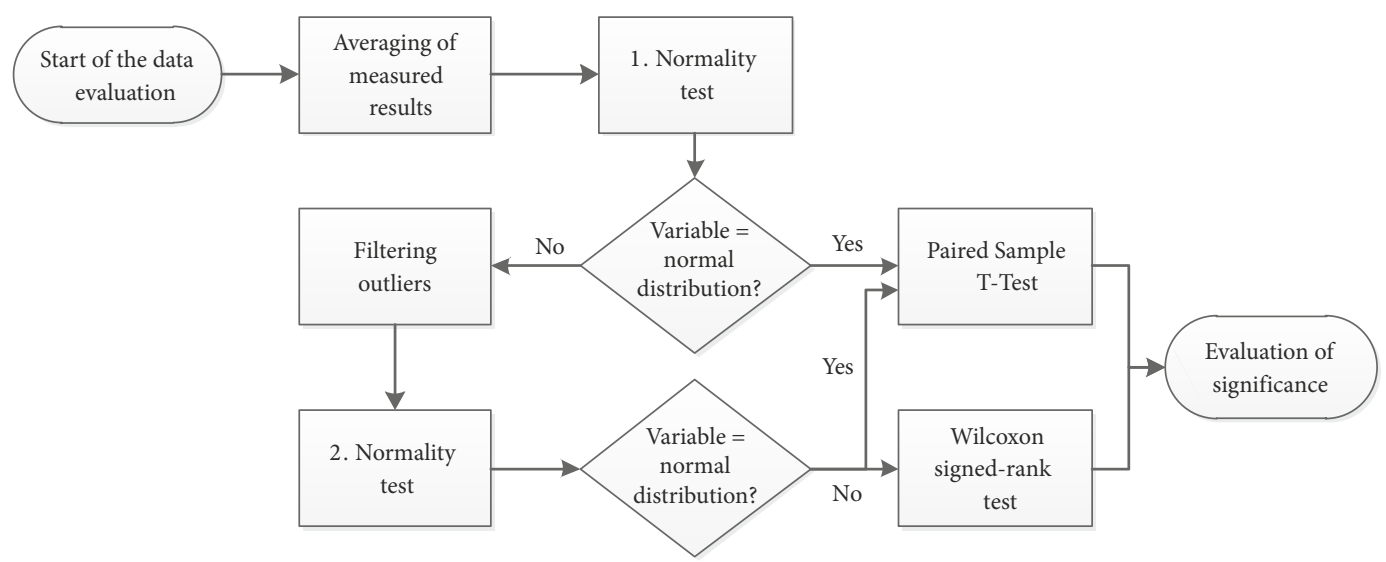

Figure 1. The evaluation process of the significance of the differences of the measured parameters 
Thereafter the 6 values of the indicators of mistakes have been summed as shown in Equation (3). The new indicator of mistakes has been calculated with this analogy for every measured person, and by each disruptive factor.

$$
\begin{aligned}
& m\left(A_{z}\right)=\frac{5 \cdot A_{z}}{\max \left(A_{z}\right)} ; \\
& z=\{r ; t ; i\},
\end{aligned}
$$

where: $A_{z}$ is the average value of "number of insufficient distance between vehicles" factor in case of disruptive factor $z$; $\max \left(A_{z}\right)$ is the maximum number of $A_{z}$ taking all examined person into account; and $m\left(A_{z}\right)$ is the scaled value of $A_{z}$.

$$
\begin{aligned}
& M_{z}=m\left(A_{z}\right)+m\left(B_{z}\right)+m\left(C_{z}\right)+ \\
& m\left(D_{z}\right)+m\left(E_{z}\right)+m\left(F_{z}\right) ; \\
& z=\{r ; t ; i\},
\end{aligned}
$$

where: $M_{z}$ is the introduced indicator of mistakes in case of disruptive factor $z$, components of the addition are the scaled values of the corresponding measured driving mistakes.

The elaborated indicators helped to evaluate the mistakes by a rating scale, instead of the determination of their number. This way, the more common, smaller mistakes get smaller weights, and greater focus was given to the more severe, rare mistakes.

\section{Results}

The described statistical tests, based on the paired comparison of the analysed data, showed the results of the comparison the data measured with and without (reference) the disruptive factors, as summarized in Table 2.

During the paired comparisons, the data measured with disruptive factors have been compared also to each other, not only to the reference rounds. Significant differences were found such as:

- the average values of indicators of mistakes, the engine speed, the average speed and the fuel consumption measured while using mobile phones show significant differences from the values measured while drinking;

- the average values braking initial speed, response time and deceleration measured while text messaging show significant differences from the ones measured while using the mobile phone and also from the ones measured while drinking.

To draw useful, practical conclusions we have analysed only the significant differences described in Table 3 in this study. The parameters of the variables showing significant differences compared to the reference measurements, and the parameters of the applied statistical tests have been

\begin{tabular}{|c|c|c|c|c|c|c|c|}
\hline $\begin{array}{l}\text { Disruptive } \\
\text { factor }\end{array}$ & Measured parameter & Dimension & $\begin{array}{l}\text { Mean } \\
\text { of } \\
\text { reference }\end{array}$ & $\begin{array}{l}\text { Measure of the } \\
\text { changes [\%] }\end{array}$ & $\begin{array}{c}\text { Significance } \\
\text { level ( } p \text {-value })\end{array}$ & $\begin{array}{l}\text { Effect size } \\
\text { of } t \text {-test }\end{array}$ & $\begin{array}{l}\text { Measure of the changes } \\
\text { based on the Wilcoxon } \\
\text { signed-rank test }\end{array}$ \\
\hline \multirow{5}{*}{$\begin{array}{l}\text { Mobile } \\
\text { phone } \\
\text { usage }\end{array}$} & indicator of mistakes & - & 7.10 & +12.2 & 0.001 & medium & - \\
\hline & engine speed & $1 / \mathrm{min}$ & 1907.40 & +6.8 & $1 \cdot 10^{-6}$ & strong & - \\
\hline & average speed & $\mathrm{km} / \mathrm{h}$ & 54.56 & -2.6 & 0.034 & - & medium \\
\hline & consumption & $1 / 100 \mathrm{~km}$ & 13.51 & +7.7 & $5.2 \cdot 10^{-5}$ & - & medium \\
\hline & response time & $\mathrm{s}$ & 0.63 & +16.8 & $1.88 \cdot 10^{-8}$ & - & strong \\
\hline \multirow{3}{*}{ Drinking } & consumption & $1 / 100 \mathrm{~km}$ & 1907.40 & +4.6 & 0.001 & - & medium \\
\hline & braking initial speed & $\mathrm{km} / \mathrm{h}$ & 100.30 & -1.3 & 0.042 & weak & - \\
\hline & response time & $\mathrm{s}$ & 0.63 & +8.3 & $2.68 \cdot 10^{-4}$ & - & medium \\
\hline \multirow{3}{*}{$\begin{array}{l}\text { Text } \\
\text { messaging }\end{array}$} & braking initial speed & $\mathrm{km} / \mathrm{h}$ & 100.30 & -9.1 & $5.98 \cdot 10^{-9}$ & strong & - \\
\hline & response time & $\mathrm{s}$ & 0.63 & +39.9 & $9.57 \cdot 10^{-13}$ & - & very strong \\
\hline & \begin{tabular}{|l|} 
deceleration \\
\end{tabular} & $\mathrm{m} / \mathrm{s}^{2}$ & 8.70 & -1.1 & $1.92 \cdot 10^{-4}$ & medium & - \\
\hline
\end{tabular}
described in Table 3.

Table 2. The significance of the differences of the measured data with disruptive factors compared to the reference measurements

\begin{tabular}{|l|l|l|l|l|}
\hline \multirow{2}{*}{ Measured parameter } & \multirow{2}{*}{ Applied statistical test } & \multicolumn{3}{c|}{$\begin{array}{c}\text { Measure of differences } \\
\text { (compared to the reference measurement) }\end{array}$} \\
\cline { 3 - 5 } & & Mobile phone usage & Drinking & \multicolumn{1}{c|}{ Text messaging } \\
\hline Indicator of mistakes & t-test & significant & non-significant & - \\
\hline Average engine speed & $t$-test & significant & non-significant & - \\
\hline Average speed & Wilcoxon signed-rank test & significant & non-significant & - \\
\hline Average fuel consumption & Wilcoxon signed-rank test & significant & significant & - \\
\hline Braking initial speed & $t$-test & non-significant & significant & significant \\
\hline Response time & Wilcoxon signed-rank test & significant & significant & significant \\
\hline Deceleration & t-test & non-significant & non-significant & significant \\
\hline
\end{tabular}

Table 3. The parameters of factors showing significant differences and the parameters of the applied statistical tests 


\section{Discussion}

The effects of the disruptive factors have been analysed by the evaluation of the changes of the driving parameters during the simulated measurements. The simulated environment provided an opportunity to perform measurements and record data under the same circumstances, changing only one disruptive factor at a time. The tested disruptive factors decrease driving skills, make difficult some driving activities demonstrably.

As a result of mobile phone usage:

- the number of mistakes made while driving, and the response time increased significantly;

- the usage of the vehicle became more difficult, the engine was operated a higher engine-speed by lower average speed, which resulted in significantly higher fuel consumption.

Phone calls distract drivers not only on a cognitive level (focus on conversation, thinking), but with the hindrance of movements (keeping one hand occupied). While the former results in the significant increase of the risk of accidents, the latter entails economic and environmental risks. The separation of the effects of the 2 different kinds of distraction can be interesting (e.g. speaking on the phone hands-free does not need the use of the hands), thus can be the subject of further research:

- As a result of drinking. The response time, and the fuel consumption increased significantly, and keeping the prescribed initial speed became more difficult. The effect of drinking was the lowest of the analysed disruptive factors. Drinking distracts drivers not on cognitive level, only by keeping one hand occupied. The more difficult handling of the gearbox entailed the increase of fuel consumption, but the frequency of mistakes did not increased significantly. The response time showed a significant increase of $8.3 \%$;

- As a result of text messaging while driving. All recorded parameters at the emergency braking task deteriorated significantly. Text messaging represents the most significant distraction, as expected, mainly by averting drivers' eyes. The response time increased significantly, almost by $40 \%$ even in the sample without outliers. In several cases during these measurements, the drivers did not notice at all, or noticed only after seconds the visual sign (these outliers were filtered by the statistical analysis). The drivers drove slower by $10 \mathrm{~km} / \mathrm{h}$ than the specified braking initial speed, and were not able to perform the same deceleration than without distraction.

Our results proved the significant effects of disruptive factors. By the application of statistical tests, our conclusions made on the analysed sample can be considered applying for the whole set of drivers. This analysis should be repeated at a larger sample as part of further research to evaluate the measure of the effects of disruptive factors separated by gender and by age groups.

To analyse in practice the effects of disruptive factors, the increase of the probability of accidental mortal- ity caused by increased response time was determined based on the results of international researches. The total stopping distance from $90 \mathrm{~km} / \mathrm{h}$ initial speed by the reference response time $(0.63 \mathrm{~s})$ is $57.42 \mathrm{~m}$ (by deceleration of $7.5 \mathrm{~m} / \mathrm{s}^{2}$ ), in case of dry road surface. The driving distance during the response time is $15.75 \mathrm{~m}$, while the braking distance is $41.66 \mathrm{~m}$. However, driving distances increase by the increased response caused by the disruptive factors (by $2.75 \mathrm{~m}$ in case of using the mobile phone, 1.25 $\mathrm{m}$ when drinking and $6.25 \mathrm{~m}$ when texting, in case of the $90 \mathrm{~km} / \mathrm{h}$ initial speed).

Thus longer response time connotes the increase of the full stopping distance. Assuming the same braking initial speed values and same deceleration values, if the driver can stop by a pop-up obstacle (such as a passenger stepping on the road) in case of reference response time, the driver will cause an accident in case of increased reference time. Knowing, that the response time increases, the hitting speeds can be calculated by Equation (4) (assuming the same initial speed and deceleration):

$$
v_{u, z}=\sqrt{v_{0}^{2}-2 \cdot a \cdot\left(s_{f, r}-t_{z} \cdot v_{0}\right)},
$$

where: $v_{u, z}$ is the impact speed in case of disruptive factor $z[\mathrm{~m} / \mathrm{s}] ; v_{0}$ is the initial speed of braking $[\mathrm{m} / \mathrm{s}] ; a$ is the deceleration $\left[\mathrm{m} / \mathrm{s}^{2}\right] ; s_{f, r}$ is the stopping distance at reference response time $[\mathrm{m}] ; t_{z}$ is the response time in case of disruptive factor $z[\mathrm{~s}]$.

The probabilities of mortality $P_{v}$ according to the given hitting speed have been determined based on the research of Rosén and Sander (2009):

$$
P_{v}=\frac{1}{1+\exp \left(6.9-0.090 \cdot v_{u}\right)},
$$

where: $v_{u}$ is the hitting speed $[\mathrm{km} / \mathrm{h}]$.

The hitting speeds and the probabilities of mortality have been summarized in Table 4, in case of response times caused by disruptive factors, by the $90 \mathrm{~km} / \mathrm{h}$ speed (according to the regulations for rural sections of national roads in Hungary), on dry road surface.

Our results showed that increased response times imply higher risks. For example, in a case, when the driver could be able to stop by a passenger stepping on the road, if text messaging, due to the increased response time the driver will hit the passenger with a $35 \mathrm{~km} / \mathrm{h}$ speed, which is fatal in 23 cases from 1000. We have to mention, that the probability of mortality by the hitting speed of $30 \ldots 35$ $\mathrm{km} / \mathrm{h}$ is higher in some studies: $8 \%$ based on the research of Anderson et al. (1997), 6\% based on the research of Pasanen (1992), and 5\% based on the research of Ashton (1980). It is also important to mention, that those significant effects detected, that the drivers can reach only lower deceleration values while text messaging, were not taken into account by these calculations.

These results have been calculated by the average deceleration values obtainable on dry roads and by $90 \mathrm{~km} / \mathrm{h}$ initial speeds. There are several different methods to estimate the probability of mortality, but the hitting speed 
Table 4 . The probabilities of mortality by increased response time caused by disruptive factors of driving (on dry roads)

\begin{tabular}{|l|c|c|c|c|}
\cline { 2 - 5 } \multicolumn{1}{c|}{} & Reference & Drinking & Mobile phone usage & Text messaging \\
\hline Initial speed $[\mathrm{km} / \mathrm{h}]$ & 90 & 90 & 90 & 90 \\
\hline Deceleration $\left[\mathrm{m} / \mathrm{s}^{2}\right]$ & 7.5 & 7.5 & 7.5 & 7.5 \\
\hline Response time $[\mathrm{s}]$ & 0.63 & 0.68 & 0.74 & 0.88 \\
\hline Distance during response time $[\mathrm{m}]$ & 15.75 & 17 & 18.5 & 22 \\
\hline Stopping distance $[\mathrm{m}]$ & 57.42 & 58.67 & 60.17 & 63.67 \\
\hline Impact speed $[\mathrm{km} / \mathrm{h}]$ & 0.00 & 15.57 & 23.11 & 34.85 \\
\hline Probability of mortality $[\%]$ & 0.00 & 0.41 & 0.80 & 2.27 \\
\hline
\end{tabular}

parameters can be calculated exactly. Figure 2 shows the hitting speed values as a result of the increased response time caused by disruptive factors in function of the braking initial speed, by deceleration values obtainable on dry $\left(7.5 \mathrm{~m} / \mathrm{s}^{2}\right)$ and wet road surface $\left(6 \mathrm{~m} / \mathrm{s}^{2}\right)$.

Higher initial speeds are associated implicitly with higher hitting speeds (thus higher probability of mortality). The stopping distances are longer on wet road surfaces, thus reducing the braking dynamics, so the increasing response distances caused by the disruptive factors mean only a smaller part of the whole stopping distance compared to dry conditions. Therefore, we got lower hitting speed results on wet blacktop compared to dry surfaces in each case.

On the one hand, it has to be emphasized that the effects of disruptive factors cannot be linked directly to the likelihood of fatal accidents, however on the other hand it has to be noted, that a strong correlation exists between disruptive factors and reaction time. In this case, the elongation of reaction time shall be assumed to increase the instantaneous velocity of the accidents. In accordance with the above-mentioned considerations, it has to be concluded that the speed of pedestrian related road accidents has surly got significant influence on severity.

\section{Conclusions}

Our research showed the significant effects of the disruptive factors, such as using the mobile phone, drinking and text messaging by the application of simulated analysis. It has been found, that the disruptive factors affect negatively the road safety by cognitive distraction and by the hindrance of movements (e.g. increasing response time, more frequent mistakes) on the one hand, and result in negative environmental and economic effects (e.g. increased fuel consumption) on the other.

The results of this research comply with the expected effects of previous investigations. The estimation of the effects of road safety can be based on these numerical results. The hitting speed was determined as an example caused by disruptive factors, from the measure of the increased response times by different speeds and environmental conditions. The method serves as an effective tool for decision makers, the legislation of the prohibition of disruptive factors can be based on the results.

This research has been carried out at a sample of 90 persons due to economic constraints. To draw conclusions for all drivers based on these results, mathematical-statistical methods have been applied to determine the signifi-

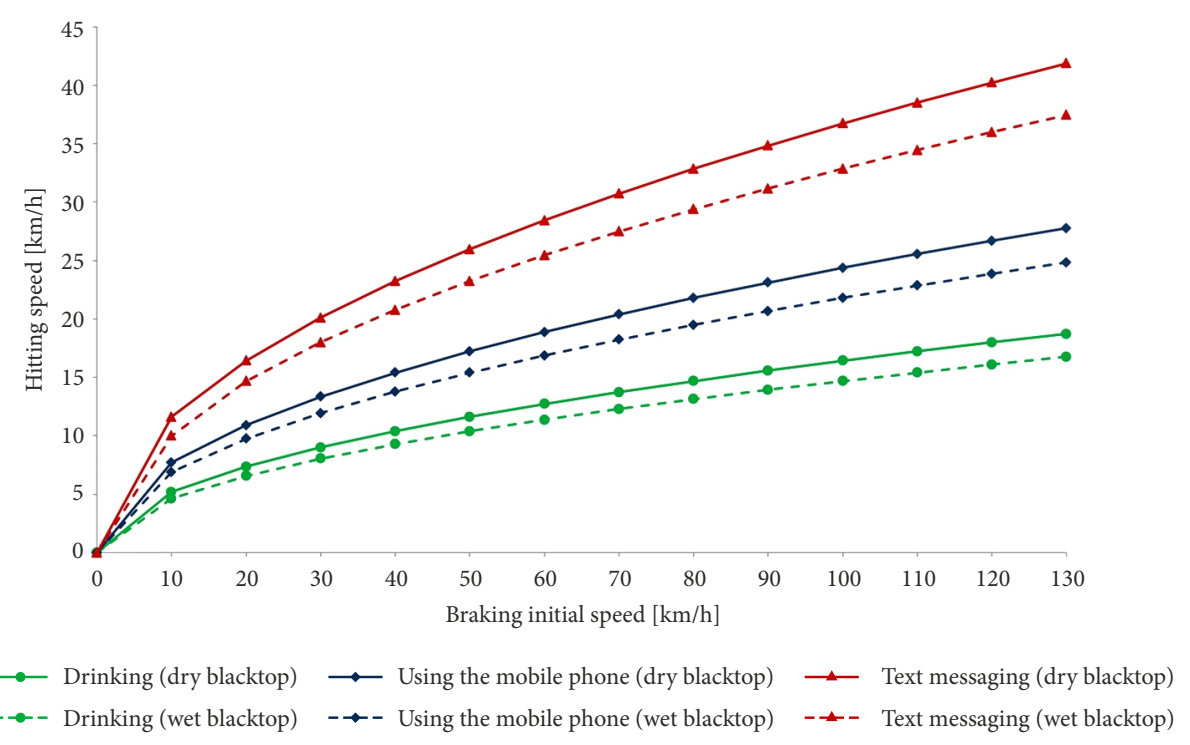

Figure 2. Hitting speeds, as a result of different disruptive factors on dry and wet road surface 
cance of the effects. Taking advantage of the benefits of the simulator, the measured persons were analysed under the same conditions changing only one parameter (the selected disruptive factor) continuously at a time. Developing the measurement conception, we aimed to eliminate the effects of other factors affecting the results (such as learning process, sickness).

As a possible continuation of this research, we plan to perform this analysis on larger samples, preferably involving more disruptive factors. This would provide an opportunity to analyse the effects of other disruptive factors on the one hand, and to separate the cognitive distraction and the hindrance of movements on the other hand. To implement the results, our future research will focus also on the equity assessment and cost benefit analysis related to the effects of the disruptive factors.

\section{References}

Amado, S.; Ulupinar, P. 2005. The effects of conversation on attention and peripheral detection: is talking with a passenger and talking on the cell phone different?, Transportation Research Part F: Traffic Psychology and Behaviour 8(6): 383-395. https://doi.org/10.1016/j.trf.2005.05.001

Anderson, R. W. G.; McLean, A. J.; Farmer, M. J. B.; Lee, B. H.; Brooks, C. G. 1997. Vehicle travel speeds and the incidence of fatal pedestrian crashes, Accident Analysis \& Prevention 29(5): 667-674. https://doi.org/10.1016/S0001-4575(97)00036-5

Ashton, S. J. 1980. A preliminary assessment of the potential for pedestrian injury reduction through vehicle design. SAE Technical Paper 801315. https://doi.org/10.4271/801315

Bartl, G.; Hager, B. 2006. Car Accident Cause Analysis. A Research Project in Cooperation with the Federal Institute for Traffic. Alles-Fuehrerschein.at GmbH, Vienna, Austria. 47 p. Available from Internet: http://traffic-psychology-international.eu/wp-content/uploads/2014/01/Bericht-Unfallanalyse2006-english.pdf

Beanland, V.; Fitzharris, M.; Young, K. L.; Lenné, M. G. 2013. Driver inattention and driver distraction in serious casualty crashes: data from the Australian national crash in-depth study, Accident Analysis \& Prevention 54: 99-107.

https://doi.org/10.1016/j.aap.2012.12.043

Beede, K. E.; Kass, J. S. 2006. Engrossed in conversation: the impact of cell phones on simulated driving performance, $A c$ cident Analysis \& Prevention 38(2): 415-421. https://doi.org/10.1016/j.aap.2005.10.015

Caird, J. K.; Johnston, K. A.; Willness, C. R.; Asbridge, M.; Steel, P. 2014. A meta-analysis of the effects of texting on driving, $A c$ cident Analysis \& Prevention 71: 311-318. https://doi.org/10.1016/j.aap.2014.06.005

Caird, J. K.; Willness, C. R.; Steel, P.; Scialfa, C. 2008. A metaanalysis of the effects of cell phones on driver performance, Accident Analysis \& Prevention 40(4): 1282-1293. https://doi.org/10.1016/j.aap.2008.01.009

Cooper, P.J.; Zheng, Y. 2002. Turning gap acceptance decisionmaking: the impact of driver distraction, Journal of Safety Research 33(3): 321-335. https://doi.org/10.1016/S0022-4375(02)00029-4

Drews, F. A.; Yazdani, H.; Godfrey, C. N.; Cooper, J. M.; Strayer, D. L. 2009. Text messaging during simulated driving, Human Factors: the Journal of the Human Factors and Ergonomics Society 51(5): 762-770. https://doi.org/10.1177/0018720809353319
Fitch, G. A.; Soccolich, S. A.; Guo, F.; McClafferty, J.; Fang, Y.; Olson, R. L.; Perez, M. A.; Hanowski, R. J.; Hankey, J. M.; Dingus, T. A. 2013. The Impact of Hand-Held And Hands-Free Cell Phone Use on Driving Performance and Safety-Critical Event Risk. Final Report No DOT HS 811757. National Highway Traffic Safety Administration, Washington, DC, US. 273 p.

Helland, A.; Lydersen, S.; Lervåg, L.-E.; Jenssen, G. D.; Mørland, J.; Slørdal, L. 2016. Driving simulator sickness: impact on driving performance, influence of blood alcohol concentration, and effect of repeated simulator exposures, Accident Analysis \& Prevention 94: 180-187.

https://doi.org/10.1016/j.aap.2016.05.008

Hermitte, T.; Reed, S.; Filtness, A. J.; Talbot, R.; Thomson, R.; Jansch, M.; Johannsen, H.; Niewohner, W.; Ancona, L.; Martin, O.; Vazquez-de-Prada, J.; Papadimitriou, E.; Phan, V.; Saade, J.; Cuny, S.; Lesire, P.; Leopold, F.; Labrousse, M. 2016. Identification of Vehicle Related Risk Factors, Deliverable 6.1 of the H2020 Project SafetyCube. Loughborough University, UK. 137 p. Available from Internet: https://www.safetycube-project.eu/wp-content/uploads/SafetyCube-D6.1-Identificationof-vehicle-related-risk-factors.pdf

Hosking, S. G.; Young, K. L.; Regan, M. A. 2009. The effects of text messaging on young drivers, Human Factors: the Journal of the Human Factors and Ergonomics Society 51(4): 582-592. https://doi.org/10.1177/0018720809341575

McKnight, A. J.; McKnight, A. S. 1993. The effect of cellular phone use upon driver attention, Accident Analysis \& Prevention 25(3): 259-265. https://doi.org/10.1016/0001-4575(93)90020-W

Moreno, E. G.; Romana, M. G. 2015. Analysis of complex dataset obtained from simulator to examine the effects of wireless telephone use on driving performance, Procedia Computer Science 52: 944-949. https://doi.org/10.1016/j.procs.2015.05.170

Neale, V. L.; Dingus, T. A.; Klauer, S. G.; Sudweeks, J. D.; Goodman, M. J. 2005. An overview of the 100-car naturalistic study and findings, in 19th International Technical Conference on the Enhanced Safety of Vehicles (ESV), 6-9 June 2005, Washington, DC, US, 1-10.

Palumbo, T. J.; Head, D.; Swift, A.; Rumschlag, G.; Ing, J.; Ngo, C.; Sur Ducan, M.; Lahoud, E.; Johnson, B.; Mackie, B.; Commissaris, R. L. 2015. The effects of texting and DUI simulation on driving performance in a driving simulator, Journal of Ergonomics S3: 013. https://doi.org/10.4172/2165-7556.S3-013

Pasanen, E. 1992. Driving Speeds and Pedestrian Safety: a Mathematical Model. Helsinki University of Technology, Finland. 41 p.

Prat, F.; Planes, M.; Gras, M. E.; Sullman, M. J. M. 2015. An observational study of driving distractions on urban roads in Spain, Accident Analysis \& Prevention 74: 8-16. https://doi.org/10.1016/j.aap.2014.10.003

Regan, M. A.; Lee, J. D.; Young, K. L. 2008. Driver Distraction: Theory, Effects, and Mitigation. CRC Press. $672 \mathrm{p}$.

Rosén, E.; Sander, U. 2009. Pedestrian fatality risk as a function of car impact speed, Accident Analysis \& Prevention 41(3): 536-542. https://doi.org/10.1016/j.aap.2009.02.002

Rumschlag, G.; Palumbo, T.; Martin, A.; Head, D.; George, R.; Commissaris, R. L. 2015. The effects of texting on driving performance in a driving simulator: the influence of driver age, Accident Analysis \& Prevention 74: 145-149. https://doi.org/10.1016/j.aap.2014.10.009

Russo, B. J.; Kay, J. J.; Savolainen, P. T.; Gates, T. J. 2014. Assessing characteristics related to the use of seatbelts and cell phones by drivers: application of a bivariate probit model, Journal of Safety Research 49: 137-142.

https://doi.org/10.1016/j.jsr.2014.03.001 
Staubach, M. 2009. Factors correlated with traffic accidents as a basis for evaluating advanced driver assistance systems, Accident Analysis \& Prevention 41(5): 1025-1033.

https://doi.org/10.1016/j.aap.2009.06.014

Stavrinos, D.; Jones, J. L.; Garner, A. A.; Griffin, R.; Franklin, C. A.; Ball, D.; Welburn, S. C.; Ball, K. K.; Sisiopiku, V. P.; Fine, P. R. 2013. Impact of distracted driving on safety and traffic flow, Accident Analysis \& Prevention 61: 63-70. https://doi.org/10.1016/j.aap.2013.02.003

Strayer, D. L.; Drews, F. A.; Crouch, J. D. 2006. A Comparison of the Cell Phone Driver and the Drunk Driver, Human Factors: the Journal of the Human Factors and Ergonomics Society 48(2): 381-391. https://doi.org/10.1518/001872006777724471

Strayer, D. L.; Drews, F. A.; Johnston, W. A. 2003. Cell phoneinduced failures of visual attention during simulated driving, Journal of Experimental Psychology: Applied 9(1): 23-32. https://doi.org/10.1037/1076-898X.9.1.23

Šucha, M. 2017. How-to-influence-behaviour model and speed choice, International Journal for Traffic and Transport Engineering 7(2): 192-202. https://doi.org/10.7708/ijtte.2017.7(2).04

Szántó, Á.; Kibédi-Varga, L. 2017. Közlekedésbiztonsági attitűdfelmérés a fesztiválozók körében, Közlekedésbiztonság 2017(2): 16-24. (in Hungarian).

Török, Á. 2017. Comparative analysis between the theories of road transport safety and emission, Transport 32(2): 192-197. https://doi.org/10.3846/16484142.2015.1062798

Treat, J. R. 1980. A study of precrash factors involved in traffic accidents, HSRI Research Review 10(6): 1-35.

Young, K.; Regan, M. 2007. Driver distraction: a review of the literature, in I. J. Faulks, M. Regan, M. Stevenson, J. Brown, A. Porter, J. D. Irwin (Eds.). Distracted Driving, 379-398.

Zefreh, M. M.; Török, Á.; Mészáros, F. 2017. Average vehicles length in two-lane urban roads: a case study in Budapest, $P e$ riodica Polytechnica Transportation Engineering 45(4): 218 222. https://doi.org/10.3311/PPtr.10744 